\title{
Raising Healthy Children: Shellfish Allergies ${ }^{1}$
}

\author{
Kate Bennett, Karla P. Shelnutt, and Gail P. A. Kauwell²
}

Learning that your child has a shellfish allergy can be scary. But having a plan and knowing how to treat and avoid a reaction to shellfish can ease this fear and keep your child safe. This publication explains shellfish allergies and provides information on the symptoms and how to respond if a reaction occurs. There are also tips to make it easier to manage your child's shellfish allergy at home and away from home.

\section{What Is a Shellfish Allergy?}

A shellfish allergy is a common type of food allergy. Food allergies occur when the immune system responds to a food as if it is harmful even though it is not (National Institute of Allergy and Infectious Disease, 2010). Children who have a shellfish allergy do not respond normally to the proteins found in crustaceans (e.g., shrimp, crab, and lobster) or mollusks (e.g., clams, mussels, oysters, and scallops). Some children are allergic to both types of shellfish. Most of the time, the allergic reaction begins after shellfish is eaten, but some children may have a reaction even if they touch shellfish or breathe in steam from shellfish being cooked.

A shellfish allergy is not the same as having an allergy to seafood. Seafood refers to shellfish and fish such as salmon, flounder, and tuna. Children who have a shellfish allergy may not be allergic to fish. Make sure you know if your child has a shellfish or a seafood allergy so you can avoid all the foods that cause a reaction. Your doctor should tell you which foods your child needs to avoid after doing allergy tests.

Food allergies can occur at any age, but your child may be at greater risk if he or she is younger than three or if there is a history of asthma (wheezing), eczema (itchy skin rash), or allergies in the family. Some children outgrow allergies to certain foods; however, shellfish allergies often last a lifetime (Food Allergy and Research Education, 2013a).

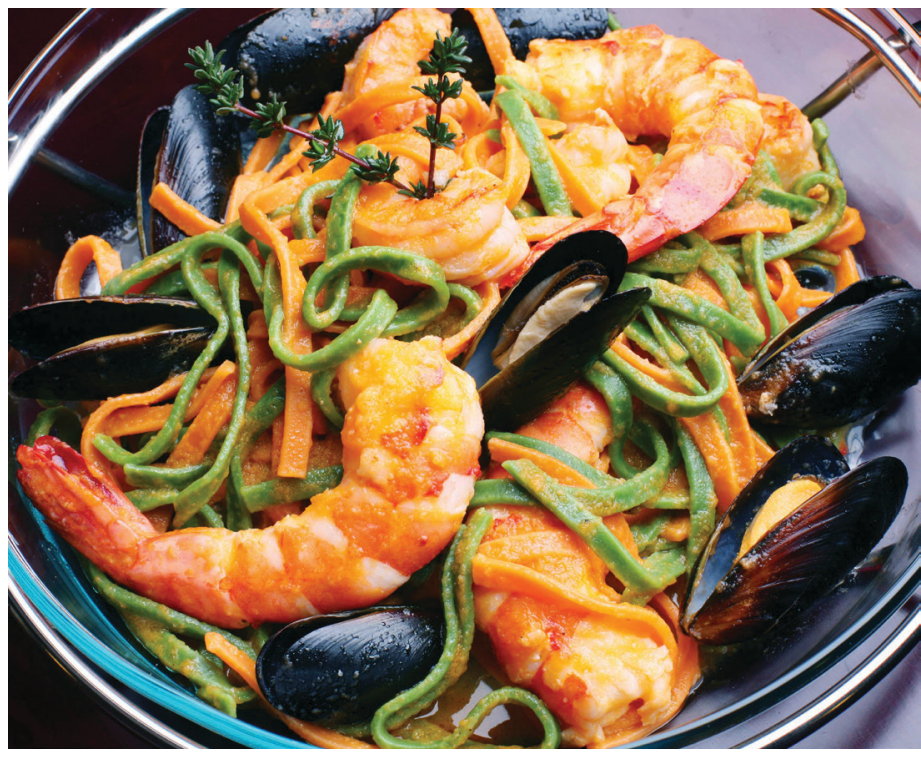

Figure 1. Children with a shellfish allergy can be allergic to crustaceans (such as shrimp, lobster, or crab) or mollusks (such as oysters, mussels, or scallops). Ask your doctor for a list of foods your child should avoid. Credits: Hemera

1. This document is FCS80033, one of a series of the Department of Family, Youth and Community Sciences, UF/IFAS Extension. Original publication date: November 2013. Visit the EDIS website at http://edis.ifas.ufl.edu.

2. Kate Bennett, BS, dietetic intern, Master of Science-Dietetic Internship Program, Food Science and Human Nutrition Department, Karla Shelnutt, PhD, RD, assistant professor, Department of Family, Youth and Community Sciences, Gail P. A. Kauwell, PhD, RD, LD/N, professor, Food Science and Human Nutrition Department; UF/IFAS Extension, Gainesville, FL 32611.

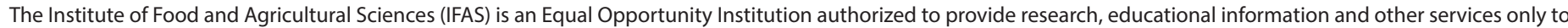

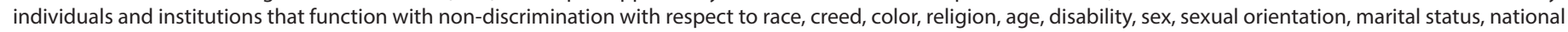
origin, political opinions or affiliations. For more information on obtaining other UF/IFAS Extension publications, contact your county's UF/IFAS Extension office. 


\section{Symptoms}

If your child has an allergy, you will need to know how to recognize the symptoms of an allergic reaction. Your child's symptoms may be different from another child's symptoms. The symptoms may also be different each time your child has a reaction. Your child may have symptoms a few minutes after coming into contact with shellfish or many hours later. Symptoms of an allergic reaction may include the following:

- Tingling in the mouth

- Itchy skin, eyes, nose, or mouth

- Eczema (itchy skin rash)

- Runny nose or sneezing

- Coughing or wheezing

- Hives (red, raised, itchy bumps on skin)

- Swelling beneath the skin and around the eyes or mouth

- Chest tightness

- Shortness of breath

- Abdominal cramps

- Vomiting or diarrhea

Extremely severe reactions may lead to the following:

- Swelling of the tongue and throat

- Difficulty breathing

- Dizziness

- Low blood pressure

- Fainting

- Loss of consciousness

Not all reactions begin the same, so react quickly to your child's symptoms even if they are mild. Symptoms that start out mild may become worse if left untreated. If you think an allergic reaction is occurring, follow the action plan given to you by your doctor. If you do not have a plan or the right medicine, take your child to the doctor right away (U.S. National Library of Medicine, 2012).

\section{Anaphylaxis}

Anaphylaxis (pronounced an-uh-fuh-lak-sis) is an extremely severe allergic reaction. It can affect multiple areas of the body and cause symptoms such as skin redness, hives, and dizziness. Other problems caused by anaphylaxis include a drop in blood pressure, which may cause your child to pass out, swelling of the throat or tongue, which may make it hard for your child to breathe, or even death. If your child is experiencing severe symptoms, take him or her to an emergency room immediately. Early treatment improves the chance of reversing the symptoms and preventing your child from going into shock or having a blockage of the airway (U.S. National Library of Medicine, 2013).

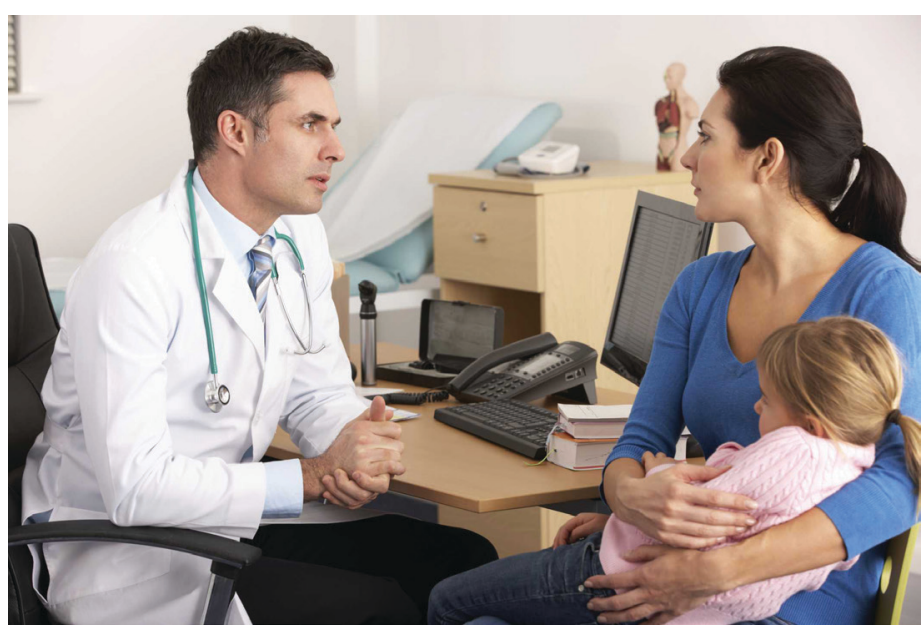

Figure 2. If your child has a shellfish allergy, ask your doctor to help you put together an action plan in case of a reaction. Credits: iStock

\section{Managing a Shellfish Allergy}

Part of managing a shellfish allergy involves learning how to keep your child from coming into contact with shellfish or foods and products that may contain shellfish.

\section{Avoiding Shellfish}

To avoid an allergic reaction, your child must completely avoid the types of shellfish he or she is allergic to. Crustaceans such as shrimp, crab, and lobster cause the majority of shellfish allergies, and many children can tolerate other types of shellfish such as mollusks, scallops, and oysters. However, to be safe, some sources recommend avoiding all types of shellfish even if your child is allergic to only one type (Tsabouri et al., 2012). Consult with your doctor about the best approach for your child.

If you are eating or handling seafood, wash your hands before touching or preparing food for your child. Also, wash all cooking surfaces and utensils to ensure that none of your child's food is contaminated by accident. Your child also should avoid touching shellfish or being in an area where shellfish is being prepared (Food Allergy Research and Education, 2013a).

\section{At the Store}

Read food labels to make sure that the type(s) of shellfish your child needs to avoid is not an ingredient in the foods you plan to serve. The ingredients list is usually located 
under the Nutrition Facts panel of the food label. Check the labels of all the foods you buy because shellfish may be present in unexpected places like sauces and seasonings. The Food Allergen Labeling and Consumer Protection Act requires that foods containing crustacean shellfish have the allergen stated on the label by a common name. The type of allergen is listed in a "contains" statement located under the ingredients list. An example of a "contains" statement looks like this: "Contains: Shellfish (Shrimp)" or "May Contain: Shellfish (Prawns)" (Food Allergy Research and Education, 2013b).

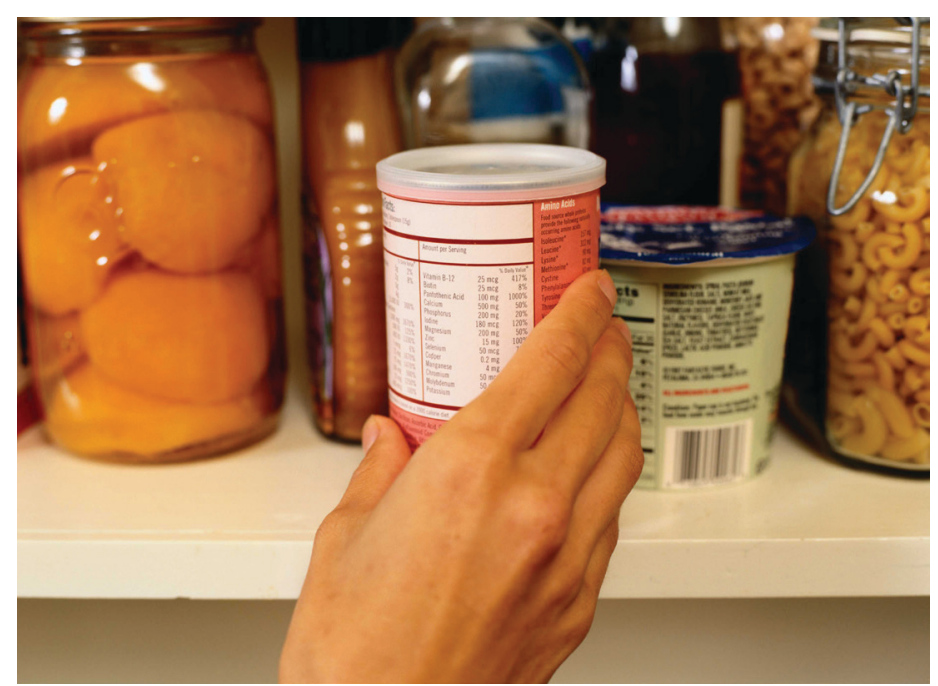

Figure 3. Check the ingredients list located under the Nutrition Facts panel to learn if foods contain shellfish. Be aware that shellfish might be in foods you don't expect, such as sauces and seasonings.

Credits: Ryan McVay, Photodisc

Foods that contain the ingredients listed below should not be served to your child if he or she is allergic to crustaceans:

- Barnacle

- Krill

- Lobster (langouste, langoustine, Moreton bay bugs, scampi, tomalley)

- Crab

- Shrimp (crevette, scampi)

- Crawfish (crawdad, crayfish, ecrevisse)

- Prawns

Mollusks are not considered a major allergen under food labeling laws, so if your child is allergic to them, you need to look extra hard to spot ingredients that might contain mollusks. These foods include the following:

- Clams

- Cuttlefish
- Sea cucumber

- Snails (escargot)

- Whelk (turban snail)

- Cockle

- Limpet

- Sea urchin

- Oysters

- Scallops

- Mollusks

- Abalone

- Mussels

- Squid (calamari)

Shellfish (mollusks or crustaceans) also may be found in the following items. If these items contain crustaceans, the name of the crustacean (e.g., shrimp, crab, or lobster) will be listed on the label. This is not true for mollusks. Use the list below as a reference:

- Bouillabaisse

- Fish stock

- Seafood flavoring

- Surimi

- Cuttlefish ink

- Glucosamine

- Crab or clam extract

- Sushi

You should also avoid products with labels that state, "This product may contain trace amounts of allergen" or "made in a facility where allergen-containing products are made." Vitamins and other supplements may contain shellfish, so read labels on these products (Food Allergy Research and Education, 2013a). This may seem like a lot to remember, but over time, managing your child's shellfish-free diet becomes easier.

\section{Eating Away from Home}

Letting your child eat outside of the home can be worrisome, especially when you are not with him or her. If your child is old enough, educate him or her about the food allergy. Be sure he or she knows which foods to avoid and emphasize how important it is to stay away from them. Also, review with your child what he or she should do if your child eats shellfish by mistake and has a reaction. Your child should be able to recognize the symptoms and 
know to seek help right away from a nearby adult. Teach your child to politely decline food offered away from home. When eating out, it is a good idea to avoid seafood restaurants. Even if your child orders a dish that does not contain shellfish, the meal might come in contact with shellfish during preparation and may contain food particles that could cause an allergic reaction.

\section{At School}

As a parent, it is your responsibility to notify school faculty and staff about your child's allergies. Ask about food allergy policies and procedures followed at your child's school, and inform the school nurse, teachers, administrators, cafeteria staff, and coaches about your child's specific needs, including which medicines should be given if a reaction occurs and how to correctly use and store them (Bugden, Martinez, Greene, \& Eig, 2011). Make sure your child understands his or her allergy and knows to avoid trading foods with friends at school and to avoid eating foods brought in by others.

\section{How to Respond to an Allergic Reaction}

Even if you feel sure that your child stays away from foods containing shellfish, accidents may happen. Know how to react in an emergency. Talk to your doctor about developing an emergency plan, and be sure you have the appropriate medicines at home and on the go. Your child may be prescribed an epinephrine auto injector, often called an EpiPen. An EpiPen is an injectable medicine used to treat serious allergic reactions. If prescribed, ask your doctor how to properly use and store your child's auto injector and make sure that anyone who cares for your child knows how to use it.

The Food Allergy Research and Education website (http:// www.foodallergy.org/faap) has a printable food allergy action plan that can be completed by you and your doctor. This useful tool can be given to your child's school, babysitters, daycare staff, or anyone else caring for your child so they can be prepared if an allergic reaction occurs.

\section{Summary}

Read food labels and make sure your child stays away from the foods that can cause a reaction and those you are not sure about. Develop an allergy action plan to follow and share this with the people who care for your child. Make sure your child carries medicine when away from you, and store it in an easily accessible place at school or daycare when your child cannot carry it. Avoid seafood restaurants, and stress the importance of hand-washing and proper cleaning of cookware and serving tools to avoid food contamination. You can reduce the chance that an allergic reaction will occur by taking these steps, staying educated, and developing a strong relationship with your child's doctor, school, and others in your child's life.

\section{References}

Bugden, E., Martinez, A., Greene, B., \& Eig, K. (2011). Safe at school and ready to learn: A comprehensive policy guide for protecting students with life-threatening food allergies. Alexandria, VA: National School Boards Association.

Food Allergy Research and Education. (2013a). Shellfish. Retrieved from http://www.foodallergy.org/page/ shellfish-allergy

Food Allergy Research and Education. (2013b). Food allergen labeling and consumer protection act. Retrieved from http://www.foodallergy.org/laws-and-regulations/falcpa

National Institute of Allergy and Infectious Diseases. (2010). What is an allergic reaction to food? Retrieved from http://www.niaid.nih.gov/topics/foodAllergy/understanding/Pages/allergicRxn.aspx

Tsabouri, S., Triga, M., Makris, M., Kalogeromitros, D., Church, M. K., \& Priftis, K. N. (2012). Fish and shellfish allergy in children: Review of a persistent food allergy. Pediatric Allergy and Immunology 23(7), 608-615.

U.S. National Library of Medicine. (2012). Food allergy. Retrieved from http://www.ncbi.nlm.nih.gov/pubmedhealth/ PMH0001820/

U.S. National Library of Medicine. (2013). Anaphylaxis. Retrieved from http://www.ncbi.nlm.nih.gov/pubmedhealth/ PMH0001847/ 